\title{
MộT Số YẾU Tố XÃ HộI LIÊN QUAN TớI STRESS SAU SANG CHẤN ở NHÂN VIÊN Y TẾ TẠII MộT Số BỆNH VIỆN KHU VỰC PHÍA BẮC VIÊTT NAM TRONG THỜI KỲ COVID-19
}

\author{
Trần Thanh Hương ${ }^{1,2}$, Trần Thơ Nhị ${ }^{1}$, Nguyễn Kim Thư ${ }^{1}$
}

\section{TÓM TẮT.}

Đắt vấn đề: Đại dịch Covid tác động rất lớn tới đời sổng kinh tế xã hội trên toàn câu, đặc biệt tới tâm lý của nhân viên y tế. Mục tiêu: xác định một số yếu tố xã hội liên quan tới stress sau sang chấn ở nhân viên y tế tai mốt số bênh viện khu vực phía Bắc Viê̂t nam trong thời kỳ Covid-19. Đối tượng và phương pháp: Thiết kế nghiên cứu ngang mồ tả, kết hợp định lượng và định tính. Bộ công cụ PSS-SR (PostStraumatic Stress Disorder Symptom Scale Self Report), sau khi được đánh giá tính giá trị, được áp dung trên 400 nhân viên y tế trực tiếp điêuu tri và chăm sóc bệnh nhân nhiễm Covid tại Bệnh viện Nhiệt đới trung ưởng và Bệnh viện đa khoa tỉnh Ninh Bình. Các yếu tố xã hội được xem xét tới gồm sự mắc bệnh của người nhà/bạn bè; kỳ thị xã hội và tác động của truyền thông. Kết quả: Tỷ lệ stress sau sang chấn của nhân viên y tế là 17,5\%; trong đó tỷ lệ ở điều dưỡng cao hơn so với bác sĩ; stress sau sang chấn ở nhân viên y tế có mối liên quan tới việc có người trong gia đình hay ban bè bi nhiêm Covid (OR= 5,$1 ; 95 \% \mathrm{CI}$ : 2,4-10,9); tự nhận thấy bị gia đình hay xã hội kỳ thị $(\mathrm{OR}=3,4 ; 95 \% \mathrm{CI}: 1,9-6,0)$, cảm thây lo lắng khi xem truyên thông $(\mathrm{OR}=4,4 ; 95 \% \mathrm{CI}: 1,9-10,2)$

Từ khóa: stress sau sang chấn (PTSD), nhân viên y tế, Covid-19; yếu tố xã hội

\section{SUMMARY}

\section{SOCIAL FACTORS RELATED TO POST- STRAUMATIC STRESS DISORDER IN HEALTH CARE STAFFS AT SOME HOSPITALS IN THE NORTH OF VIETNAM DURING COVID-19 PANDEMIC}

Background: Covid-19 pandemic had impact to social economic life in global, especially to mental health of health care staffs. Objectives: To identify some social factors related to post- straumatic stress disorders in health care staffs from some hospitals in the North of Vietnam during Covid-19 pandemic. Methods: Cross-sectional study with combined quantitative and qualitative method. PSS-SR scale was applied to 400 health care staffs who directly treated and cared for patients infected Covid-19. Theses staffs were from the National Tropical Disease Hospital and Ninh Binh General Hospital. Social factors were considered included family members/friends infected

\footnotetext{
${ }^{1}$ Trường Đại học Y Hà Nội

2 Viện Ung thư quốc gia

Chiu trách nhiệm chính: Trân Thanh Hương

Email: huongtran2008@gmail.com

Ngày nhận bài: 14.6.2021

Ngày phản biện khoa học: 6.8.2021

Ngày duyệt bài: 16.8.2021
}

Covid-19; social stigma and impact of social media. Results: Rate of PTSD in health care staffs was $17.5 \%$, higher in nurses. PTSD in health care staffs correlated with person who had friends or family memebers infected Covid-19 (OR= 5.1; 95\%CI: 2.4 10.9); social stigma (OR $=3.4 ; 95 \% \mathrm{CI}$ : 1.9-6.0), worries when received information from social media $(\mathrm{OR}=4.4 ; 95 \% \mathrm{CI}: 1.9-10 ., 2)$

Keywords: Post-straumatic Stress Disorder, health care staffs, Covid-19, social factors

\section{I. ĐĂT VẤN ĐÊ}

Tính đến ngày $10 / 11 / 2020$, trên toàn câu đã có 51,3 triệu ca nhiễm và 1,27 triệu ca tử vong do Covid-19 [1]. Con số này đã cho thây mức độ nguy hiểm và diễn biến phức tạp của dịch bệnh Covid-19 trên toàn thế giới. Các nhân viên y tế, những cán bộ tham gia công tác phòng chống Covid-19 không những đối mặt với nguy cơ cao nhiễm bệnh mà còn dể gặp phải các triệu chứng tâm lý và triệu chứng tâm thân khác nhau [2]. Những áp lực này có thể do nhân viên y tế phải cách ly với gia đình; công việc căng thẳng; có nguy cơ lây nhiễm bệnh... vì vậy có thể xuất hiện các rối loan tâm lý như stress, lo âu, trâm cảm. Các rối loạn stress này có thể kéo dài và trở thành nỗi "ám ảnh" của nhân viên y tế cho tới cả sau khi đai dich qua đi. Tai môt nghiên cứu ở Trung Quốc trên nhân viên y tể tỷ lệ trầm cảm lên tới $50,4 \%$; có triệu chứng căng thẳng sau sang chấn là 71,5\% [3], [4].

Rối loạn căng thẳng sau sang chấn (PTSD: Post traumatic stress disorders) là tình trang tâm thân không ổn định bao gồm khủng hoảng, hồi hộp, trâm cảm do chấn động lớn xảy ra trong quá khứ gây ra [5]. Cho tới nay, Việt Nam là quốc gia đã kiểm soát thành công đại dich Covid. Tuy nhiên, cũng như các quốc gia khác, vấn đề sức khỏe tâm thân của nhân viên y tế, đặc biệt của nhân viên y tế làm viêc trực tiếp tai các đớn vị điều trị Covid ra sao thực sự là vấn đề cân được quan tâm. Theo sự phân công của Bộ Y tế, Bệnh viện Nhiệt đới Trung ương cơ sở Kim Chung và Bệnh viện đa khoa Ninh Bình là 2 Bệnh viên thuốc khu vức miền Bắc điều tri nhiều bểnh nhân Covid nhất. Chính vì vậy chúng tôi thực hiện nghiên cứu này nhằm xác định một số yểu tố xã hội liên quan tới stress sau sang chấn ở nhân viển bênh viện trong đại dich Covid-19 tại 
một số bệnh viện khu vực phía bắc, Việt Nam năm 2020.

\section{II. ĐỐI TƯƠNGG VÀ PHƯƠNG PHÁP NGHIÊN CỨU}

2.1. Địa điểm nghiên cứu: Bệnh viện Bệnh Nhiệt đới Trung ương cơ sở Kim Chung và Bệnh viện Đa khoa tỉnh Ninh Bình.

2.2. Thời gian: $1 / 6 / 2020-30 / 10 / 2020$

2.3. Đối tượng nghiên cứu: Nhân viên làm việc tại bệnh viện trong khoảng thời gian từ ngày đầu tiên bệnh viện tiếp nhận điều trị bệnh nhân nhiễm Covid-19 đến ngày 31/05/2020.

Tiêu chuẩn lựa chọn: Nhân viên làm viêc tại bệnh viện có chăm sóc điều trị bệnh nhẩn Covid-19.

Thời gian làm việc từ ngày đầu tiên bênh viên tiếp nhận điều trị bệnh nhân nhiễm Covid-19 đển ngày $31 / 05 / 2020$.

Đối tượng đồng ý tham gia nghiên cứu.

Tiêu chuẩn loại trừ: Nhân viên làm việc tại bệnh viện ngoài thời gian từ khi bệnh viện tiếp nhận bệnh nhân Covid-19 đến 01/05/2020.

Đối tượng không đồng ý tham gia nghiên cứu

2.4. Thiết kế nghiên cứu: Nghiên cứu mô tả cắt ngang, sử dụng kết hợp phương pháp nghiên cứu định lượng và định tính.

2.5. Cỡ mẫu và cách chọn mấu:

Nghiên cứu định lượng: chọn tất cả các nhân viên y tế tại 2 bệnh viện đã và/hoăc đang điều trị, chăm sóc bệnh nhân Covid-19 đáp ứng các tiêu chuẩn lựa chọn. Số nhân viên tại 2 bệnh viện tham gia nghiên cứu là 400 .

Nghiên cứu định tính: Phỏng vấn sâu 15 nhân viên ở 2 bệnh viện bao gồm 10 nhân viên ở bệnh viện Bệnh Nhiệt đới Trung ương, 5 nhân viên ở Bệnh viện Đa khoa tỉnh Ninh Bình. Trong đó bao gồm: 03 bác sĩ trực tiếp điều trị bệnh nhân Covid-19, 06 điều dưỡng trực tiếp chăm sóc bệnh nhân Covid-19. 03 nhẩn viên khác nhân viên khác có phơi nhiễm với Covid-19, 03 điều dưỡng/bác sĩ không tiếp xúc với bệnh nhân nhiễm Covid-19.

2.6. Biến số nghiên cứu: bao gồm các yếu tố xã hội liên quan tới stress sau sang chấn, kỳ thị từ cộng đồng, hỗ trợ từ xã hội, ảnh hưởng thông tin từ truyền thông và một số yếu tố cá nhân (tuổi, giới, tình trạng hôn nhân...)

2.7. Công cụ nghiên cứu: sử dụng bộ câu hỏi đánh giá rối loạn căng thẳng sau chấn thương PSS-SR (Post-Straumatic Stress Disorder Symptom Scale Self Report). Bộ công cụ này được đánh giá tính giá trị trước khi thực hiện, với hệ số Cobrach's Alpha là 0,88

2.8. Quy trình nghiên cứu: nghiên cứu được thực hiện theo các bước sau: (1) Nộp hồ sơ nghiên cứu thông qua Hôii đồng đao đức nghiên cứu (2) Chuẩn hóa bộ công cụ PSS-SR (3) Liên hệ với Ban lãnh đạo của 2 Bệnh viện tham gia nghiên cứu để xin phép được thu thập số liêu (4) Tâp huấn cho nhóm nghiên cứu (5) Tổ chức thu thập số liệu; (6) Phân tích số liệu và viết báo cáo

\subsection{Quản lý và phân tích số liệu}

Với số liệu định lượng: Các phiếu trả lời được làm sạch và đánh mã trước khi nhập liệu. Số liệu định lượng được nhập trên phần mềm Epidata 3.1 và phân tích bằng phần mềm thống kê Stata 12.0. Mức ý nghĩa thống kê sử dụng trong nghiên cứu là $p<0,05$, khoảng tin câyy $95 \%$.

Với số liệu định tính: Các băng định tính được ghi âm dưới dạng file mp3. Mổi file được đánh mã băng định tính gồm 5 ký tự: XXXXX. Băng ghi âm được gõ băng thành văn bản, nhập bằng file Word. File nhập Word phân tích theo chủ đề bằng file Excel. Các ý kiến tiêu biểu được chọn lọc và trích dẫn trong phần kết quả theo mục tiểu và chủ đề nghiên cứu.

2.10. Đạo đức nghiên cứu: Nghiên cứu được phê duyệt bởi Hội đồng đạo đức trong nghiên cứu của

\section{KẾT QUẢ NGHIÊN CứU}

Có 400 nhân viên y tế làm việc tại các Khoa trực tiếp điều trị bệnh nhân Covid và đồng ý tham gia nghiên cứu, trong đó nữ giới chiếm $63,5 \%$; số nhân viên có tuổi trên 35 chiếm $21 \%$; nhân viên y tế là bác sĩ chiếm $27 \%$; điều dưỡng chiếm $47,7 \%$.

Bảng 1. Tỷ lệ stress sau sang chấn của nhân viên y tê

\begin{tabular}{|c|c|c|c|c|c|c|c|}
\hline \multirow{2}{*}{$\begin{array}{c}\text { Stress sau } \\
\text { sang chấn }\end{array}$} & \multicolumn{2}{|c|}{$\begin{array}{c}\text { Bệnh viện đa khoa } \\
\text { Ninh Bình }\end{array}$} & \multicolumn{2}{|c|}{$\begin{array}{c}\text { Bệnh viện Nhiệt đới } \\
\text { trung }\end{array}$} & \multicolumn{2}{|c|}{ Tởng } & \multirow{2}{*}{ p } \\
\cline { 2 - 7 } & $\mathbf{n}$ & $\mathbf{\%}$ & $\mathbf{n}$ & $\mathbf{\%}$ & $\mathbf{n}$ & $\mathbf{\%}$ & \\
\hline Có & 21 & 15,0 & 49 & 18,1 & 70 & 17,5 & \multirow{2}{*}{0,33} \\
\hline Không & 119 & 85,0 & 211 & 81,2 & 330 & 82,5 & \\
\hline
\end{tabular}

Tỷ lệ stress sau sang chấn của nhân viên y tế là $17,5 \%$. Tỷ lệ này tại Bệnh viện nhiệt đới trung ương cao hơn so với Bệnh viện đa khoa Ninh Bình (tỉ lệ tương lần lượt là $18,1 \%$ và $15 \%$ ). Tuy nhiên sự khác biệt này không có ý nghĩa thống kê (Bảng 1)

Bảng 2: Phân bồ tỷ lệ stress sau sang chẩn theo trình độ chuyên môn của nhân viên y tế 
VIETNAM MEDICAL JOURNAL N²2 - AUGUST - 2021

\begin{tabular}{|c|c|c|c|c|}
\hline \multirow{2}{*}{$\begin{array}{c}\text { Stress sau sang chấn } \\
\text { (PTSD) }\end{array}$} & \multicolumn{2}{|c|}{ Có } & \multicolumn{2}{|c|}{ Không } \\
\cline { 2 - 5 } & $\mathbf{n}$ & $\mathbf{\%}$ & 86 & 21,5 \\
\hline Bác sĩ & 23 & 5,8 & 152 & 38,0 \\
\hline Điều dưỡng & 39 & 9,8 & 3 & 0,8 \\
\hline Hộ lí & 1 & 0,3 & 89 & 22,3 \\
\hline Khác & 7 & 1,8 & 330 & 82,5 \\
\hline Tống & 70 & 17,5 & n
\end{tabular}

Bảng 2 cho thấy điều dưỡng là nhóm đối tượng có tỷ lệ stress sau sangc hấn cao hơn so với các nhóm đối tượng khác với tỷ lệ ở điều dưỡng là $9,8 \%$; bác sĩ là $5,8 \%$ và hộ lí; khác lần lượt là $0,3 \%$ và $1,8 \%$.

Bảng 3: Môi liên quan giữa yêu tố gia đình-xã hội và stress sau sang chấn ở nhân viên y tế

\begin{tabular}{|l|c|c|c|} 
Yếu tố gia đình-xã hội & PTSD; n (\%) & Không PTSD; n (\%) & OR (95\%CI)
\end{tabular} Có người thân, bạn bè mắc Covid-19

\begin{tabular}{|c|c|c|} 
Không & $54(14,8)$ & $311(85,2)$ \\
\hline
\end{tabular}

Có $16(47,1)$ $18(52,9)$ 1

Bị bạn bè, gia đình, cộng đồng xa lánh, kì thị vì là nhân viên y tế

\begin{tabular}{|c|c|c|c|}
\hline Không & $22(9,9)$ & $199(90,1)$ & 1 \\
\hline Có & $48(27,3)$ & $128(72,7)$ & $3,4(1,9-6,0)$ \\
\hline \multicolumn{4}{|c|}{ Gia đình bị cộng đồng xa lánh, kỳ thị vì là nhân viên y tế } \\
\hline Không & $30(11,7)$ & $227(88,3)$ & 1 \\
\hline Có & $40(28,4)$ & $101(71,6)$ & $3(1,7-5,1)$ \\
\hline Nhận được sự hô̂ trợ tinh thần, vật chất từ bạn bè, gia đình, cộng đồng \\
\hline Có & $60(16,7)$ & $300(83,3)$ & 1 \\
\hline Không & $10(25,0)$ & $30(75,0)$ & $1,7(0,8-3,6)$ \\
\hline \multicolumn{2}{|c|}{ Cảm thấy lo lăng mồi khi xem các thông tin trên truyên thông } \\
\hline Không & $7(6,0)$ & $109(94,0)$ & 1 \\
\hline Có & $62(22,1)$ & $218(77,9)$ & $4,4(1,9-10,2)$ \\
\hline
\end{tabular}

Kết quả cho thấy có mối liên quan có ý nghĩa thống kê giữa tỷ lệ stress sau sang chấn của nhân viên y tế với việc có người thân bạn bè bị mắc Covid-19 (OR=5,1; 95\%CI=2,4-10,9); bị bạn bè, gia đình, cộng đồng xa lánh, kì thị vì là nhân viên y tế $(\mathrm{OR}=3,4 ; 95 \% \mathrm{CI}=1,9-6,0)$; Gia đình bị cộng đồng xa lánh, kỳ thị vì là nhân viên $y$ tế $(\mathrm{OR}=3 ; 95 \% \mathrm{CI}=1,7-5,1)$; cảm thây lo lắng mỗi khi xem các thông tin trên mạng $(\mathrm{OR}=4,4$; $95 \% \mathrm{CI}=1,9-10,2)$.

Bên cạnh những kết quả nghiên cứu định lượng, chúng tôi đã có những buổi phỏng vấn sâu nhân viên y tế. Thái độ kỳ thị của xã hội không chỉ là những câu truyện chỉ có trên tivi, nó còn hiển hiện ngay trên những nhân viên y tế của chúng ta. Mặc dù những nhân viên y tế, khi họ được về nhà họ đã được xét nghiệm, đã được sự cho phép của bệnh viện, nhưng 1 số nhẩn viên y tế cũng không tránh khỏi sự kỳ thị của hàng xóm, xã hội.

"Bình thường mình về mình vẫn chơi với mọi người. Thế nhưng mà cái đợt mình ở đây ra thì mọi người cũng không muốn mở cửa. Thế mình thấy thế thì mình cũng không sang nhà họ nữa." (BS Th, nam)
Sự nỗ lực trong công việc của các nhân viên y tế là điều đáng được khen ngợi, tuy nhiên, trên thực tế, họ luôn gặp phải những ánh mắt, lời nói hay hành động kỳ thị của cộng đồng ở những mức độ khác nhau. Một bác sĩ tại khoa truyền nhiễm có chia sẻ:

Trước khi về nhà, mình đã cách ly đủ 14 ngày nhưng mà hàng xóm người ta cũng không muốn tiếp xúc với mình. Tâm lý họ cũng sợ là mình lây sang họ. Bình thường mình về mình vẫn chơi với mọi người, thế nhưng mà cái đợt mình ở đây ra thì mọi người cũng không muốn mở cửa. Thế mình thấy thế thì mình cũng không sang nhà họ nữa (BS TA, 54 tuổi, nam)

Chúng tôi đã khóc theo điều dưỡng L., một điều dưỡng bệnh viện đa khoa Ninh Bình, khi chị kể cho chúng trong những giọt nước mắt không cầm được, về sự kỳ thị của hàng xóm, không chì cho bản thân chị mà là cho những đứa con bé bỏng của chị.

"Con chị hàng xóm đóng cửa ý, họ không cho vào (chị khóc). Về con chị bảo anh Quang Anh đóng cửa anh không cho con vào chơi thì mình biết lúc đấy nhà người ta..." (ĐD L, 32 tuổi, nữ) 
Chính thái độ kỳ thị, làm cho nhiều nhân viên y tế có nhà không dám về, dù đã hết cách ly, đã được xét nghiệm âm tính. Họ không phải chỉ lo lắng cho bản thân họ, có thể họ lo lắng nhiều hơn là gia đinh, con cái họ, cũng phải chịu sự kỳ thị ấy.

"Thời điểm hai tháng mình cũng có thể về được và mình có thể biết được mình hoàn toàn an toàn vì mình đã xét nghiệm và đã cách li đủ ngày. Nhưng mà chính vì vẩn đề tâm lý nên là em không ra bởi vì khi mình về mọi người vẫn còn lo sợ, lo tiếp xúc với mình. Sau đó thì vì mình về nên mọi người sẽ lo ngại tiếp xúc với người thân của mình, tiếp xúc với bố mẹ mình. Khi đó vị thế của mình đang là anh hùng phòng chống dịch (cười) lại bị mọi người quay lưng lại" (BS Th, nam)

\section{BÀN LUÂ̂N}

Tỷ lệ PTSD của nhân viên y tế là $17,5 \%$. Trong đó Bệnh viện nhiệt đới trung ương cao hơn so với Bệnh viện đa khoa Ninh Bình (tỉ lệ tương lần lượt là $18,1 \%$ và $15 \%$ ). Điều này có thể do bệnh viện NDTW tiếp nhận và điều trị nhiều bệnh nhân COVID hơn BV ĐK Ninh Bình. Tuy nhiển sự khác biệt này không có ý nghĩa thống kê. Tỷ lệ này cao hơn căng thẳng sau sang chấn của nhân viên y tế cũng được thể hiện ở hâuu hết các nghiên cứu với cùng một thang điểm IES-R tại Singapore và Trung Quốc 7,4\% [2], nghiên cứu khác ở Singapore là 7,7\% [6]. Tuy nhiên tỉ lệ này lại thấp hơn rất nhiều so với nghiên cứu của Trung Quốc là 71,5\% [4]. Có thể giải thích rằng dịch COVID-19 đã gây ra tác động nặng nề đối với Trung Quốc cũng như gây nên gánh nặng cho ngành y tế, nên con số $71,5 \%$ của nhần viên bệnh viện PTSD đã phản ánh đúng hậu quả của dịch bệnh tại Trung Quốc.

Trong thời gian chống dịch, nhân viên y tế đã không được về nhà mà phải cách ly trong bệnh viện, vì vậy ho không được gặp gia đình mình, không được tiếp xúc với xã hội. Điều này cũng ảnh hưởng không nhỏ đến tâm lý của nhân viên y tế. Nghiên cứu của chúng tôi cho thấy có mối liên quan có ý nghĩa thống kê giữa tỷ lệ stress của nhân viên y tế với những người có người thân hay ban bè bị mắc Covid-19 ( $\mathrm{OR}=6,5$; $95 \% \mathrm{CI}=2,7-15,7)$. Trực tiếp điều trị và chăm sóc cho bệnh nhân nhiễm Covid-19 nên nhân viên y tế, hơn ai hết hiểu được sự khó khăn và vất vả cũ̃ng như khả năng lây truyền của bệnh. Nỗi lo lắng sẽ tăng lên nhiều lần khi vẫn phải ở trong bệnh viện để chăm sóc bệnh nhân trong khi người thân của mình lại nhiếm bệnh mà mình lại không được trực tiếp chăm sóc.

Kết quả nghiên cứu của chúng tôi cũng cho thấy kỳ thị và truyền thông là một trong những yếu tố khiến cho nhân viên y tế bị stress sau sang chấn. Nghiên cứu cắt ngang tại 5 bệnh viện lớn, ở Singapore và Ấn Độ trên 906 nhân viên y tế (480 Singapo và 426 Ấn Độ) sử dụng thang đo DASS21 và IES-R25 đánh giá triệu chứng rối loạn căng thẳng sau sang chấn (PTSD). Những người tham gia được yêu câuu đánh giá mức độ đau khổ cho từng thành phần trong bảy ngày trước, những cán bộ y tế có người thân bạn bè nhiễm Covid-19 có thực trạng căng thẳng cao gấp 3,74 lần [6]. Một số yếu tố gia đình khác được đề cập trong các nghiên cứu gồm: Sự kỳ thị từ gia đình, bạn bè, hỗ trợ từ gia đình (vật chất và tinh thấn). Một số yếu tố xã hội được đề cập trong các nghiên cứu gồm: Hỗ trợ xã hội, ảnh hưởng thông tin từ truyền thông, sự kì thị của cộng đồng [2][7]. Sở dĩ có sự kỳ thị này có thể do các nguyên nhân như sau: bản thân Covid-19 là căn bệnh mới xuất hiện nên chưa có các thuốc điều trị triệt để; kiến thức về phòng bệnh của người dân còn hạn chế và một trong những lý do rất quan trọng là việc truyền thông thái quá khiến người dân và cộng đồng kỳ thị với người nhiễm cũng như nhân viên y tế trực tiếp chăm sóc bênh nhân Covid.

Mặc dù tỷ lệ lây nhiễm Covid-19 giảm nhẹ, tác động đến sức khỏe tâm thần của nhân viên y tế có thể tạo ra những tác động lâu dài. Cuối cùng, một số bằng chứng cho thây tác động đáng kể về mặt thời gian trong việc giảm xếp hạng triệu chứng stress sau sang chấn, báo cáo mức giảm $50 \%$ sau một tháng. Ngược lại, một số báo cáo cho rằng nhân viên y tế thựcc hiện một tháng trước các nhiệm vụ liên quan đến dịch bệnh có nguy cơ cao hơn đối với các triệu chứng của PTSD ngay cả khi thời gian đã trôi qua, và nguy cơ gia tăng khi ngủ và các triệu chứng liên quan đến tê, đặc biệt nễu cách ly tại nhà được thực hiện. Như vậy cần quan tâm tới vấn đề tư vấn tâm lý cho nhân viên y tế không phải chỉ trong thời gian đại dịch mà còn cần kéo dài cả sau đại dịch [8], [9].

\section{KẾT LUẬN}

Tỷ lệ stress sau sang chấn của nhân viên y tế là 17,5\%; trong đó tỷ lệ ở điều dương cao hơn so với bác sĩ; stress sau sang chấn ở nhân viên y tế có mối liên quan tới việ̂c có người trong gia đình hay bạn bè bị nhiểm Covid $(\mathrm{OR}=5,1$; 95\%CI: 2,4-10,9); tự nhận thấy bị gia đình hay xã hội kỳ thị $(\mathrm{OR}=3,4 ; 95 \% \mathrm{CI}: 1,9-6,0)$, cảm 
thấy lo lắng khi xem truyền thông $(\mathrm{OR}=4,4$; 95\%CI: $1,9-10,2$ )

\section{TÀl LIẸU THAM KHẢO}

1. Cục Y tế Dự phòng, Bộ Y Tế (2020). COVID-19 DASHBOARD. $h$ https://ncov.vncdc.gov.vn/>, accessed: 30/05/2020.

2. Chew N.W.S., Lee G.K.H., Tan B.Y.Q. và công sứ. (2020). A multinational, multicentre study on the psychological outcomes and associated physical symptoms amongst healthcare workers during COVID-19 outbreak. Brain, Behavior, and Immunity.

3. Pappa S., Ntella V., Giannakas T. và cộng sự. (2020). Prevalence of depression, anxiety, and insomnia among healthcare workers during the COVID-19 pandemic: A systematic review and meta-analysis. Brain Behav Immun.

4. Lai J., Ma S., Wang Y. và cộng sự. (2020). Factors Associated With Mental Health Outcomes
Among Health Care Workers Exposed to Coronavirus Disease 2019. JAMA Netw Open, 3(3).

5. National Institutes of Health (2019). PostTraumatic Stress Disorder. <https://www.nimh.nih.gov/health/topics/posttraumatic-stress-disorder-ptsd/index.shtml>, accessed: 15/05/2020.

6. Tan B.Y.Q., Chew N.W.S., Lee G.K.H. và cộng sư. (2020). Psychological Impact of the COVID19 Pandemic on Health Care Workers in Singapore. Ann Intern Med.

7. WHO (2017), Depression and Other Common Mental Disorders, World Health Organization.

8. Lai J., Ma S., Wang Y. và công sứ. (2020). Factors Associated With Mental Health Outcomes Among Health Care Workers Exposed to Coronavirus Disease 2019. JAMA Netw Open, 3(3).

9. Zhang W., Wang $K .$, Yin $L$. và cộng sự. (2020). Mental Health and Psychosocial Problems of Medical Health Workers during the COVID-19 Epidemic in China. Psychother Psychosom, 1-9.

\section{MộT SỐ ĐĂC ĐIỂM CẤU TRÚC SO MĂT Ở TRẺ EM NGƯờI KINH TỪ 7-9 TUỔI TRÊN PHIM SỌ NGHIÊ̂NG THEO PHÂN TÍCH RICKETTS}

\section{Trương Đình Khởi ${ }^{1}$, Lương Ngọc Khuê ${ }^{2}$, Đào Thị Dung ${ }^{3}$, Hà Ngọc Chiều ${ }^{1}$, Đinh Diệu Hồng ${ }^{3}$ \\ CRANIOFACIAL CHARACTERISTICS IN KINH ETHNIC CHILDREN FROM 7 TO 9 YEARS OF AGE ON LATERAL CEPHALOGRAMS USING RICKETTS ANALYSIS \\ Objectives: To determine craniofacial}

\section{TÓM TẮT}

Muc tiêu: Xác định một số đăc điểm so mă̆t và phân tích sự tăng trưởng đâu mặ̆t từ 7-9 tuổi trên phim sọ nghiêng sử dụng phân tích của Ricketts. Đối tượng và phương pháp nghiên cứu: Nghiên cứu dọc trên 206 trẻ $7-9$ tuổi người Kinh tại trường Tiểu học Liên Ninh, Thanh trì, Hà Nội bằng phương pháp đo trên phim so nghiêng kỹ thuất số. Kết quả: Chiều cao mặt toàn bộ (Ba-N/Xi-Pm), chiều cao tầng mặt dưới (Ans-Xi-Pm), góc măt phẳng hàm dưới (Go$\mathrm{Me} / \mathrm{Fh}$ ) sự khác biệt không có ý nghĩa thống kê giữa nam và nữ ở trẻ 7 tuổi, nhưng ở loai III lớn hơn loai I và II Angle. Chiều cao mặt toàn bộ và chiều cao mặt dưới không đổi ở loại I Angle, tăng trưởng đều đặn ở loại II và III Angle từ 7-9 tuổi. Góc mặt phẳng hàm dưới giảm theo tuổi ở loại I Angle, tăng dần theo tuổi ở loại II và III Angle. Kết luận: Các chỉ số đặc điểm so mắt ở trẻ 7 tuổi người Kinh giống nhau giửa nam và nữ, xu hướng nữ tăng trưởng sớm hơn nam.

Tư khóa: Chiều cao mặt toàn bộ, chiều cao mặt dưới, góc mặt phẳng hàm dưới

\section{SUMMARY}

${ }^{1}$ Viện Đào tạo Răng Hàm Mặt- Đại học Y Hà Nội ${ }^{2}$ Cục Khám chữa bệnh và Cục Y tế dự phòng-Bộ y Tế,

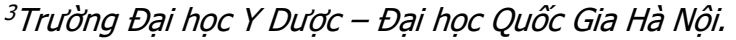
Chiu trách nhiếm chính: Trương Đình Khởi

Email: bskhoirhm@gmail.com

Ngày nhận bài: 11.6.2021

Ngày phản biện khoa họ: 2.8.2021

Ngày duyệt bài: 12.8.2021 characteristics and evaluate the growth of Kinh ethnic children from 7 to 9 years old on lateral cephalograms. Subjects and methods: A longitudinal study of 206 children (104 males, 102 females) from 7 to 9 years old in Lien Ninh primary school, Thanhtri, Hanoi by measuring on lateral cephalograms according to Ricketts analysis. Results: Average of total facial height (Ba-N/Xi-Pm), lower facial height (Ans-Xi-Pm) and mandibular plan angle (Go-Me/Fh) were no difference between male and female in 7 years old children, but in class III was larger in class I and II Angle. Conclusion: Most of craniofacial dimensions were no difference between male and female, craniofacial growth in female was significantly sooner than in male.

Keywords: total facial height, lower facial height, mandibular plan angle

\section{I. ĐĂT VẤN ĐỀ}

Chỉnh hình răng mặt trở thành nhu câu của xã hội, trong đó, từ 7-9 tuổi là thời điểm quan trọng trong điêu trị dự phòng và can thiệp sớm, nhờ vào đánh giá đặc điểm nhân trắc đâuu mặt mà các bác sỹ lâm sàng có thể hiểu rõ hơn tình trạng bệnh lý, tiên lượng được xu hướng tăng trưởng để quyết định kế hoạch điêu trị và có thể 